\title{
"Saudade e rusticidade": a convivência com o semiárido entre grandes pecuaristas do Nordeste
}

\section{Valdênio Freitas Meneses* [1]}

\section{Resumo $^{\mathrm{a}}$}

No início do século XXI, a ideia de convivência com o semiárido - ou convivência com as secas - foi identificada junto a movimentos sociais e políticas públicas direcionadas às populações mais pobres no meio rural do Nordeste brasileiro. Assim, consolidou-se uma crítica ao modelo de grandes obras de combate à seca e contra uma histórica dominação das elites de grandes proprietários de terra. Atento a esse debate, este artigo evidencia uma versão da convivência com o semiárido que tem direção política e simbólica favorável à grande propriedade rural na região semiárida brasileira. Trata de como frações de elites pecuaristas do Nordeste construíram uma ideia de convivência com as secas, desde final dos anos 1970, através de cruzamentos de discursos da Superintendência de Desenvolvimento do Nordeste (Sudene), de entidades patronais de grandes pecuaristas regionais, até editoriais da imprensa especializada alinhados à Associação Brasileira de Criadores de Zebu (ABCZ). Diferente da convivência com o semiárido de pastorais, ONGs e redes, como Articulação para o Semiárido (ASA), o projeto pecuarista de superação do

\footnotetext{
* UNINASSAU, Campina Grande, PB, Brasil.

a Este artigo é resultado de pesquisas feitas entre 2012-2018, dentro de um projeto de mestrado no PPGCS/UFCG e outro de doutorado no CPDA/UFRRJ. O argumento aqui apresentado foi desenvolvido no quarto capítulo da tese "Saudade e rusticidade: reconversões sociais e convivência com as secas entre elites pecuaristas do Cariri Paraibano", defendida em 2018 e vencedora do "Prêmio Capes de Tese 2019" na área de Sociologia. Este trabalho pode ser consultado na íntegra no seguinte link <https://sucupira.capes.gov.br/sucupira/public/consultas/coleta/trabalhoConclusao/ viewTrabalhoConclusao.jsf?popup $=$ true\&id_trabalho $=6584492>$.
} 
combate às secas posiciona centenárias fazendas como local legítimo, por excelência, de produção de conhecimentos, de tradições passadas a técnicas modernas para conviver com as estiagens. Identificada essa convivência "conveniente" à grande propriedade pode-se mapear um campo de disputas entre múltiplas versões da convivência com o semiárido. A partir disso o artigo conclui com proposta de atualizar uma agenda de debates sobre a relação entre elites, secas e poder no Nordeste. ${ }^{a}$

Palavras-chave: convivência com o semiárido, elite pecuarista, Nordeste.

\section{The senses of the living with the drought among large cattle ranchers in the Brazilian Northeast}

\section{Abstract}

At the beginning of the 21 st century, the idea of living with the drought was consolidated as a critical alternative to the political domination of the large landowner elite. Also, this concept was used for social movements and a set of public policies directed towards the consequences of droughts in the Brazilian Northeast. Less known, however, is the construction of a new legitimacy for the large rural property in Brazil's semi-arid region, in which fractions of Northeast livestock elites built an idea of living with droughts. This paper analyzes how these political agenda, which have been in place since the late 1970s, have redirected founding speeches: Northeast Development Superintendence (Sudene) in media editorials aligned with the Brazilian Zebu Breeders Association (ABCZ) and other regional associations of large ranchers. Unlike the political idea of living with droughts held by catholic church movements - "Pastorais da Terra" and CEBs (Comunidades Eclesiais de Base), NGOs etc. - the project of landlords to living with the droughts makes a symbolic defense of the large estates: the livestock farm would be the place of knowledge production, from reviving old traditions to developing new techniques to learn how to live with the droughts. By tracing a field of disputes between multiple versions of living with droughts, this paper seeks to refresh the sociological debate around elites, droughts and power strategies in the Brazilian Northeast.

Keywords: living with droughts, livestock elite, Brazilian Northeast. 


\section{Introdução}

$\mathrm{E}$

ste artigo busca analisar como a bandeira da convivência com as secas foi produzida entre grandes proprietários pecuaristas do Nordeste. Isso implica uma perspectiva sobre percepções de mudanças climáticas e relações de poder, tema que tem provocado as ciências sociais a revisitar paradigmas clássicos. Essa ótica do poder na relação sociedade-natureza pressiona por uma abordagem interdisciplinar ${ }^{1}$, como mostrou recente dossiê desta revista (Almeida, 2019). Aqui direciono o debate para o vínculo das elites com as secas no Nordeste. Essa pauta de pesquisa já apresenta um acúmulo considerável de trabalhos que, inclusive, fizeram da região Nordeste a mais estudada em diferentes áreas das ciências humanas do Brasil. Não é à toa que o próprio conceito geográfico dessa região seja resultado de embates políticos e acadêmicos que envolvem a relação entre poder e secas. Assim mostra o debate de diferentes correntes e autores lideradas pelos "três do Nordeste" cada qual com obras já clássicas que firmaram divergentes "linhagens" acadêmicas: Manuel Corrêa de Andrade (Terra e homem no Nordeste), Francisco de Oliveira (Elegia para uma re(li) gião) e Durval Albuquerque Jr. (Invenção do Nordeste) (Vesentini, 2012). Se o dito popular "chover no molhado" traduz algo repetitivo, um assunto já resolvido, o "eterno" retorno das elites à evocação das secas no semiárido nordestino está longe de ser um tema concluído e sem polêmicas, tendo em vista a reconstrução de estratégias para impor visões de mundo que buscam monopolizar cultural, política e economicamente uma região bastante diversa.

"Colaboração essa que jamais será harmônica. Ao "mergulhar" nas controvérsias que o debate sobre mudança climática gera entre diferentes cientistas e epistemologias, Taddei e Haines (2019) evidenciam uma visão "encantada" da intersdisciplinaridade: se há proximidade, por exemplo, entre cientistas sociais e meteorologistas, ela se dá muito mais pela via conflituosa - tal qual aliança de "inimigos" da filosofia relacional dos ameríndios - e contraria expectativas de um "consenso" harmônico. Tal qual os xamãs amazônicos, há cientistas que usam de tradução entre mundos - e mesmo de uma metamorfose de si mesmos - e assim transitam na forte estrutura acadêmica que divide ciências e evita "contaminações" (Taddei; Haines, 2019, p. 204). 
No caso aqui estudado, trato da posição de poder de elites específicas: os pecuaristas no Nordeste, grupo que teve forte base não apenas fundiária e econômica mas na política parlamentar e com influência identitária regional durante quase todo século XX (Meneses, 2018). Essa posição sofreu abalos diante de mudanças sociais significativas na transição entre os séculos XX e XXI. Desde final dos anos 1980, uma "tempestade" tem abalado o mercado da exportação algodoeira e pecuária: de crises fiscais, às pragas do "bicudo", até a dissolução dos sistemas de trabalho e moradia. Assim, as fazendas perderam capacidade de produção e mão de obra. Também ficou reduzido o raio de influência econômica das fazendas a partir da consolidação da constituição de 1988, que traz uma rede de políticas de combate à pobreza, programas de transferência de renda, previdência social, acesso à crédito e aumentos na renda salarial (Bacelar, 2010). O fluxo migratório de mão de obra, rural-urbano e Nordeste-Sudeste, que marcou boa parte do século XX, foi transformado. Do outro lado, há mudanças nas relações de gênero, identidade e até gostos, consumo, estilos de vida. Pesquisas registram novas estratégias e projetos de vida das mulheres beneficiárias do Bolsa Família que firmam sua autonomia emancipando-se dos maridos e até abdicando dos casamentos para se posicionarem como "chefes de família, gestoras da casa" (Rego; Pinzani, 2014, p. 13). Até os valores conservadores e patriarcais trazem "novidades": o machismo musical se descola do regionalismo da fazenda - do vestuário de couro das letras do forró de Luiz Gonzaga - e passa cada vez mais a ser identificado com "a masculinidade dos potentes carros de som e estilos de vida de classes média e alta urbanas" (Albuquerque Jr., 2010, p. 77).

Portanto, há um giro de transformações sociais no final do século XX, que faz com que os pecuaristas nordestinos sofram não somente crises econômicas, mas o risco de desclassificação nos recursos de poder e distinção, algo indispensável para uma elite. É exatamente nesse período de crise que foram consolidadas as estratégias de setores pecuaristas que colocam a convivência com o semiárido como defesa simbólica da grande propriedade da terra. Além da atenção a esse recorte histórico, é preciso 
diálogo teórico em torno da questão: quais condições sociais tornam possível um discurso da convivência com o semiárido que é conveniente à grande propriedade? Para questões como essa, aciono a teoria sociológica com base na proposta de poucos trabalhos que fazem um balanço crítico da construção da bandeira de convivência com o semiárido: este é o caso em Moreira Neto (2013) e em Cunha e Paulino (2014). Mesmo que não olhem as elites - e tomem como fonte apenas movimentos sociais e debates acadêmicos -, esses trabalhos "desencantam" o discurso da convivência, trazendo à tona conflitos e contradições inerentes à elaboração dessa forte bandeira política. Tomo também como referência nessas pesquisas o uso do conceito de campo para demarcação de diferentes agentes e instituições ligadas à convivência com o semiárido. Essa é a perspectiva² de microcosmos sociais relativamente autônomos de Pierre Bourdieu (2004a; 2004b). Ao operar esse conceito, a sociologia bourdieusiana propôs fugir de armadilhas nas teorias e estudos sociológicos. Primeiro, as análises do fetiche das internalidades: comum em estudos pós-modernos, essa visão orienta teorias que analisam a literatura, por exemplo, "como se os textos falassem por si, sem atenção ao contexto e às externalidades" (Bourdieu, 2004a, p. 19). Por outro lado, há os determinismos dos fatores externos, a exemplo de estudos influenciados por certa visão marxista, que entregam todo texto ao contexto. As estruturas reais estariam além das "particularidades internas, sendo determinadas e subordinadas às relações econômicas" (Bourdieu 2004a, p. 19). Portanto, é para o escape a esses exageros, sejam eles internalistas ou externalistas, que serve a categoria de campo. No tema aqui abordado, a perspectiva de campo permite não só mapear um microcosmo de agentes e relações sociais, suas forças internas e externas, mas também reconstruir diversos caminhos pelos quais foi (é) produzido e legitimado um sistema de percepções sociais comuns, chamado de convivência com o

${ }^{2}$ Para análises e revisões recentes do conceito de campo ver dossiê do número 200 da Actes de la Recherche en Sciences Sociales, organizado por Patrick Champagne (2013). 
semiárido, que possui uma forma de senso de jogo, illusio ${ }^{3}$, que aproxima militantes de movimentos sociais aos grandes pecuaristas.

O artigo está organizado em três partes. Na primeira, apresento como foi produzida a crença da convivência com as secas entre grandes proprietários pecuaristas. Trato do projeto de uma "pecuária tropical" propagada, desde início do século XX, por entidades como a Associação Brasileira de Criadores de Zebu (ABCZ), junto a um recorte no projeto de desenvolvimento presente no Grupo de Trabalho para o Desenvolvimento do Nordeste (GTDN), documento fundador da Sudene (1959). Utilizo como fonte o acervo virtual de revistas ligadas às entidades pecuaristas do Nordeste: Paraíba Pecuária (1976-1979) e Agropecuária Tropical (1979-1987). Também é fonte deste artigo o livro A revolução nordestina: a epopeia das secas (1500-1983), publicado pelo jornalista Rinaldo dos Santos (1984), editor chefe das referidas revistas. A segunda parte trata da abordagem da convivência com as secas por setores da igreja e movimentos sociais do campo, tomando por base marcos para a redemocratização brasileira dos anos de 1980. Utilizo como fonte edições do periódico O Candeeiro (2009-2013), além do livro Semiárido: uma visão holística, de Roberto Malvezzi (2007) - todos porta-vozes da rede Articulação para o Semiárido Brasileiro (ASA). Na terceira parte do artigo, após um mapeamento de diferentes convivências com o semiárido, aponto que, apesar de diferenças inconciliáveis entre as "convivências" de movimentos sociais e de grandes pecuaristas, ambas convergem em um senso de jogo que se baseia em um monopólio que enclausura o semiárido de forma homogênea como espaço rural agropecuário e, assim, negam demandas urbanas para o problema das secas.

\footnotetext{
${ }^{3} \mathrm{Um}$ exame minucioso que envolve debate sobre o termo illusio na sociologia de Pierre Bourdieu pode ser visto no trabalho de Pedro Paulo de Oliveira (2005).

${ }^{4}$ Parte do acervo desta revista está disponível no arquivo virtual do site do Centro de Referência da Pecuária Brasileira: <http://www.zebu.org.br/Revistas/Index/Memorias-doZebu $>$. Como o site está sendo reformulado, deixo disponível o acervo usado na pesquisa que deu origem a esse artigo no link: https://drive.google.com/open?id=1Ldj-MgrKp2bp_ iMq-r1TkpQoyUXB6Jsp> .
} 


\section{Uma convivência com o semiárido conveniente à grande propriedade pecuarista}

Expressão de ideias-força de uma condição de classe, os argumentos do chamado ruralismo - o apelo à "vocação agrária" do país "celeiro do mundo" e a defesa incansável do chamado "homem do campo" - não "brotaram" espontaneamente: têm sido construídos em editoriais, matérias e manifestos publicados em revistas patrocinadas por frações e entidades representativas do "patronato rural brasileiro desde, pelo menos, a Primeira República" (Mendonça, 2005, p. 412). Trata-se de um projeto ambivalente de modernidade que se expressa até a mais recente posição do agronegócio se faz como palavra política: a atualização de uma visão de classe tornada ideologia pela missão do Brasil enquanto "celeiro do mundo"; um ethos que se apresenta moderno e tecnológico junto a uma visão de propriedade que se aproxima mais de valores patrimoniais: a defesa de uma violência, "simbólica e às vezes física e direta em prol da grande propriedade" (Bruno, 2009, p. 217).

No caso dos pecuaristas nordestinos, há um ethos proprietário - com afinidades eletivas com uma ideia de convivência com as secas - expresso em revistas como Paraíba Pecuária e Agropecuária Tropical. Antes de tudo, essas publicações têm ligação "umbilical" com a $A B C Z$, que tem raízes políticas e históricas nos embates em torno da importação de raças zebuínas indianas, feita por pecuaristas mineiros no início do século XX (18981928) (Medrado, 2015). Esse foi um momento da transição, no Brasil, do que se chamava de pastoreio - técnicas de criação de gado vindas do período colonial - para uma pecuária modernizada e racionalizada. A introdução do gado zebu indiano pelos pecuaristas mineiros foi marcada por "forte resistência e disputa por parte dos paulistas - daí iniciou o que 
ficou conhecido na imprensa nacional como 'a guerra contra o Zebu'" 5 (Medrado, 2015, p. 272).

O apoio institucional do governo do presidente Getúlio Vargas ${ }^{6}$ foi um marco de vitória das sociedades de pecuaristas do Triângulo Mineiro junto aos pecuaristas de São Paulo. De 1935 a 1938, o Ministério da Agricultura oficializou a execução dos Registros Genealógicos das Raças Bovinas de Origem Indiana, registrando animais puros por cruzamento em regime de Livro Aberto, o que estabeleceu o pedigree do Zebu em todo território nacional (Leal, 2016). A Sociedade Rural dos Triangulinos - que se tornaria ABCZ em 1967 - configurou-se como o projeto de uma pecuária tropical, unindo potente mercado de investimento genético e, principalmente, de articulação política de famílias de zebuzeiros junto ao poder do Estado. Essa "pecuária dos trópicos" apoiou-se na invenção de um imaginário nacional entre elites de raças de bovinos e de famílias de criadores (Leal, 2016, p. 282). Tal projeto, que fundou a $A B C Z$, irá encontrar-se com os valores e percepções sobre propriedade da terra e secas da elite pecuarista nordestina em um momento histórico específico: o da implementação de propostas de modernização pela Superintendência de Desenvolvimento do Nordeste (SUDENE). Nesse "Cruzamento" de ideias está uma das gêneses da bandeira de convivência com as secas dessa elite.

De fato, há muitas afinidades entre os pecuaristas do Nordeste e o ethos empresarial rural do agronegócio (Bruno, 2009) ou os grandes pecuaristas

\footnotetext{
${ }^{5}$ Foi marcante na "Guerra do Zebu", segundo historiadora Joana Medrado (2015), a resistência de membros da então Sociedade Nacional de Agricultura (SNA) à introdução do gado indiano no rebanho brasileiro. Tanto que a I Conferência Nacional da Pecuária, realizada no Rio de Janeiro, em 1917, não apresentou qualquer atividade relacionada ao Zebu. Em resposta, pecuaristas do Triângulo Mineiro começaram a se alinhar junto à política estadual e organizaram encontros locais para compartilhar informações sobre zebuinocultura - o primeiro deles aconteceu em 1906 e foi sediado em fazendas de Uberaba.

${ }^{6}$ Há uma fotografia bastante simbólica na história da relação entre poder nacional e pecuária no Brasil: a de Getúlio Vargas, marcando com ferro quente a perna de um animal durante exposição em Belo Horizonte, em 1937 (Paraíba Pecuária, n. 4, 1978, p. 25). No caso da exposição de Uberaba, nenhum presidente da república, desde Vargas, deixou de visitar o evento anual: isso é indicativo do poder de barganha da pecuária de elite brasileira nas articulações nacionais de poder (Leal, 2016, p. 275).
} 
brasileiros do gado Zebu, de circuitos de Uberaba-MG (Leal, 2016). Contudo, é importante demarcar especificidades desse grupo social cujos membros reivindicam a distinção de serem autênticos "sertanejos e nordestinos". As revistas dos setores pecuaristas trazem uma relação não apenas afetiva mas também política com narrativas de ocupação territorial do sertão "na pata do gado", da exaltação saudosa da chamada "Civilização do couro", termo que circulou entre memorialistas, folcloristas e escritores do Brasil colonial. Para os pecuaristas, essa expressão, mesmo que represente uma já defasada análise historiográfica ${ }^{7}$, evoca símbolos de poder e prestígio.

Essa ordem social passada, exaltada na convivência dos grandes pecuaristas com as secas, também tem sua gênese atrelada a uma lógica de relações de dominação, que seguiu vigente após a abolição da escravidão em parte considerável da grande propriedade rural no Brasil. Tal lógica pressupunha o consórcio de uma produção para exportação - entre a criação de gado e relações de trabalho distantes da lógica jurídica e assalariada ${ }^{8}$ que recrutava famílias de agricultores, sitiantes, posseiros e homens pobres livres; em suma, grupos identificados com um tipo de campesinato com restrito ou nenhum acesso à propriedade oficial da terra. No caso de boa

${ }^{7}$ As fragilidades historiográficas dessa visão foram evidenciadas em trabalhos sobre abastecimento nos sertões, como o de Francisco Carlos Teixeira (1997) [não está na lista], que mostram uma leitura mais diversificada do processo histórico dos sistemas de abastecimento e ocupações de terra entre os séculos XVI e XVIII. As narrativas de que o gado foi se afastando dos canaviais e adentrou os interiores do Brasil colônia fazem esquecer a diversidade e a complexidade dos caminhos coloniais nos sertões: disputas locais e territoriais de sesmeiros, posseiros, foreiros, que circulavam nas vastas demarcações da coroa portuguesa.

${ }^{8}$ Essa economia de produção exportadora e as hierarquias entre proprietários e trabalhadores rurais foram legitimadas por vínculos sociais com diversos nomes: "moradia", "agregados", "trabalho alugado", "cambão", "terça" ou "sujeição", dentre outros que variavam conforme tempo, local e tipo de atividade nas grandes propriedades. Em termos materiais, a "troca" entre proprietários da terra e trabalhadores agregados podia ser feita através de múltiplas funções na fazenda - como agricultores em épocas de colheita e plantio, vaqueiros, empregados da casa sede, jagunços etc. Em termos simbólicos, os agregados se "sujeitavam" aos fazendeiros dentro de prestações e compromissos regidos por códigos de conduta e hierarquia que, no geral, pouco incluíam contratos jurídicos ou salariais - baseavam-se em reciprocidades desiguais de bens, compadrio, parentesco, amizade e até ameaças com uso de violência física e intimidade sexual (Ribeiro, 2010, p. 398). 
parte da grande propriedade pecuarista, na atual delimitação do semiárido nordestino ${ }^{9}$, a tendência foi de que a produção exportadora algodoeira e a pecuária bovina dessem movimento a uma sociedade que viveu intensos fluxos de modernização e inserção em mercados, notadamente entre o século XIX e metade do século XX em zona dos Sertões da Borborema (Nunes, 2016) . Outra dinâmica política da grande propriedade pecuarista do Nordeste foi a coerção do voto, por meio da qual políticos oriundos de famílias proprietárias construíram eleitorado e redes de compromissos: assim, o poder local da grande fazenda pecuarista alcançou o nível das decisões no Estado brasileiro ao longo de quase todo século XX, com o jogo de parlamentares vindos de famílias e oligarquias rurais da República Velha (Lewin, 1993).

Outro tema é o forte tom saudosista do regionalismo nordestino defendido pelas elites pecuaristas locais, notadamente vindo da literatura e das artes. Seja visto como expressão ideológica de relações sociais de produção (Oliveira, 1981), seja como regularidade de discursos de saberpoder (Albuquerque Jr., 2011), há o registro de uma poderosa construção regionalista ${ }^{10}$ nas obras de intelectuais descendentes das elites agrárias em decadência: Gilberto Freyre, Rachel de Queiroz, José Américo de Almeida, José Lins do Rêgo, até folcloristas, como Câmara Cascudo, e músicos que ganharam relevância na difusão radiofônica nacional no Rio de Janeiro, nos anos 1950, como Luiz Gonzaga.

\footnotetext{
${ }^{9}$ Embora já se falasse de semiárido desde pelo menos o GTDN de 1959, a região só veio a ser instituída legalmente em 1989, delimitando uma área de atuação da Sudene com pluviometria inferior a $800 \mathrm{~mm}$. Essa classificação foi atualizada pelo Ministério da Integração Nacional (2005), em conjunto com um Grupo de Trabalho Interministerial (GTI)] e tem a mais recente delimitação do Semiárido brasileiro incluindo regiões de todos os estados do Nordeste (com exceção do Maranhão) e norte de Minas Gerais, a partir de critérios tais como a precipitação pluviométrica, índice de aridez e risco de seca maior que $60 \%$.

${ }^{10}$ Uma novidade - principalmente em relação ao viés marxista - trazida pelo trabalho de Albuquerque Jr. é que não foi só a retórica de nostalgia de elites decadentes, mas também a produção cultural de esquerda que demarcou e tornou visível uma singularidade do Nordeste: um território de revolta, da pobreza rural, do messianismo, do retirante que desafia a ordem, do cangaço e da revolução social iminente no Brasil - vide os trabalhos do escritor Graciliano Ramos e do cineasta Glauber Rocha (Albuquerque Jr., 2011, p. 207).
} 
O Nordeste rural como espaço da saudade, da "tradição" e da "cultura original" brasileira é fruto de um singular cruzamento histórico de processos políticos, econômicos, culturais, climáticos e naturais. Aí também estão condições de produção de recursos sociais de distinção da elite pecuarista. São valores que carregam saudosismo e tradições, mas que elaboram e demandam produtos estritamente modernos. Uma "saudade" expressa na exaltação bucólica da grande propriedade da terra pela evocação de um passado centenário da "conquista" dos sertões secos e de uma "rusticidade" - palavra-chave dos criadores em defesa de um projeto político via pecuária competitiva e que traz a proposta de conviver com os ciclos de estiagem. Apresentados como "carimbados de antiguidade", esses discursos saudosos e rústicos só vieram a ter visibilidade consolidada depois da primeira década do século XX. Acompanham a criação relativamente recente da imagética regional e "sertaneja", ideário este inexistente até o início do século XX: a região era chamada de "Norte" do Brasil e, portanto, não havia Nordeste enquanto unidade política, econômica e geográfica no imaginário nacional (Albuquerque Jr., 2011, p. 33).

Essa construção de "nordestinidade", simpática aos pecuaristas, será tensionada diante de transformações vindas da intensificação da modernização do Estado brasileiro - entre os governos Vargas e Juscelino Kubitschek (JK). Na região Nordeste, esse momento político será marcado pela fundação da Sudene, em 1959: ligada diretamente ao governo JK, propunha, em seu documento fundador - feito pelo superintendente Celso Furtado e assinado como Grupo de Trabalho para Desenvolvimento do Nordeste (GTDN) -, uma leitura desenvolvimentista diante do grave problema da disparidade regional entre a economia do Centro-Sul e o Nordeste do Brasil. Os estudos de impacto para criação da Sudene, resumidos no documento, propõem alternativas ao que chama de "solução hidráulica", modelo de grandes obras de irrigação e açudagem para lidar com as secas. Nessa proposta, havia a ideia de que se deve aprender a conviver com as secas dinamizando uma pecuária sustentada durante 
os períodos secos em forragens arbóreas que se adaptem às condições mesológicas que "poderiam constituir o núcleo de uma economia de elevado grau de resistência às secas e de razoável nível de produtividade" (...) (Furtado, 2009, p. 145-147).

Nesse momento, uma dramatização política que já atravessava a criação de órgãos como DNOCS ${ }^{11}$ e $\mathrm{BNB}^{12}$ vai ganhar intensidade nos espaços de planejamento da Sudene. Esse ideário modernizador forçará certos padrões e visões de mundo dos setores pecuaristas que reagiram ativamente contra o novo modelo de planejamento. Há forte crítica de representantes da elite pecuarista no congresso nacional dirigidas à Sudene e ao seu superintendente Celso Furtado: figuras, como o senador e pecuarista paraibano Argemiro de Figueiredo, acusaram a proposta de convivência com as secas da Sudene de querer "tirar água do povo". Celso Furtado um economista de formação keynesiana - "seria acusado de comunista em virulentos discursos feitos por Figueiredo, entre 1961-1962, na tribuna do Senado" (Meneses, 2017, p. 97).

Nos 15 anos após o golpe civil-militar, houve uma "pacificação" e incorporação seletiva dessas propostas originais da Sudene. Durante a ditadura civil-militar, a superintendência, além de prestar investimento de crédito, assistência técnica e engenharia entre convênios com fazendas (Santos, 1987, p. 22), também teve parte de sua matriz ideológica capturada pelos setores pecuaristas. Estes faziam uma seletiva defesa de propostas do projeto original da Sudene desde que retiradas pautas da industrialização, urbanização e reforma agrária - nesse sentido, havia disputas dos pecuaristas

${ }^{11}$ DNOCS foi criado em 1909, com o nome de IOCS, já resultado de debates anteriores nas escolas politécnicas do Rio de Janeiro, que instituíram as secas como problema científico (Ferreira et al., 2009, p.2).

${ }^{12} \mathrm{O}$ Banco do Nordeste do Brasil foi criado em 1952, com finalidade de financiamento público/privado de obras de infraestrutura, e auxílio nas obras de emergências. A ideia foi formulada pelo então ministro da fazenda Horácio Lafer, em 1951: estrutura de financiamento, mais um grupo de estudos (ETENE) para diagnosticar potencialidades e fragilidades da economia regional. Seguia o aumento de orçamento público para combate às secas já iniciado na base do DNOCS desde 1930 (Marcondes; Dandaro, 2018). 
com elites urbanas, comerciais, financeiras dentre outras. O ideal era o reforço de demandas de modernização técnica nas fazendas pecuaristas. Por serem representantes de um passado - da memória ${ }^{13}$, tradição e vocação agrária do Nordeste -, essas fazendas deveriam ser prioridade de políticas de crédito, experimentos agrícolas e zootécnicos via EMBRAPA além de obras de infraestrutura de transportes garantidas pelo Estado.

Esta operação ideológica sobre valores políticos da Sudene pode ser reconstruída através das páginas da Agropecuária Tropical. Com o nome inicial de Paraíba Pecuária, essa revista começou a circular no segundo semestre de 1976, com periodicidade bimestral. Patrocinada pela ABCZ e suas filiais regionais, a Sociedade Nordestina de Criadores (SNC) e a Sociedade Rural da Paraíba (SRP), a revista lançaria no editorial "Conversa ao pé da porteira" sua missão: estabelecer-se como porta-voz do empresariado rural nordestino, lembrando que o "alicerce de toda nação reside na exploração do solo (...) e que não se deve perder de vista o Nordeste e o Brasil como celeiro do mundo" (Paraíba Pecuária, 1976, p. 5).

É em torno desses valores que o termo convivência com as secas passa a ser utilizado com mais frequência durante os anos que ficaram conhecidos como os da "Grande Seca" que teve ciclos mais intensos de 1979 a 1984. Nesse período, os editoriais, artigos e reportagens da Agropecuária Tropical trazem propostas, definições, projetos e políticas regionais para o problema das secas no Nordeste. É exemplar uma sequência de seis páginas na edição de no 29, de dezembro de 1982. Um manifesto da convivência com as secas entre grandes pecuaristas, o artigo "As regras do desenvolvimento: o modelo nordestino" propõe uma filosofia a ser seguida:

conviver com o clima austero não tem nada de trágico, muito pelo contrário, é positivamente indicado para um sem número de explorações com boa

${ }^{13}$ Há um aspecto dessa convivência com as secas que trata da transformação de centenárias fazendas em locais de memória, como museus particulares, arquivos, publicação de livros de genealogia etc. Para uma pesquisa sobre o tema, ver Meneses (2019) sobre as biografias dos "patriarcas" de famílias proprietárias de centenárias fazendas da região do Cariri paraibano. 
rentabilidade (...). A seca não poderá continuar sendo apenas uma fatalidade, de certo modo irremediável. É o componente natural e definitivo da vida nordestina e há que se buscar a conciliação com ela (Agropecuária Tropical, n. 29, 1982, p. 4-5).

O argumento do texto ainda coloca que projetos voltados para a seca no Nordeste são ditados por regras feitas em "gabinetes refrigerados de Brasília, por técnicos que não sobrevivem da economia rural do semiárido" (Agropecuária Tropical, n. 29, 1982, p. 6). Em razão disso, o texto defende que o setor agropecuário da região Nordeste foi alijado no orçamento nacional, tendo seus investimentos desviados para usos exclusivos de serviços em áreas urbanas e distritos industriais das grandes cidades localizadas no Centro-Sul do Brasil. Os editores da revista clamam por um planejamento patriótico que comece a privilegiar o desenvolvimento em conciliação com as regiões secas, obedecendo a "mandamentos" de quem vive no campo e, assim, sabe aproveitar uma melhor economia no clima semiárido. Ao priorizar as potencialidades do mercado de carne, leite e peles, o artigo encerra alertando para as "falsas convivências com as secas a perímetros irrigados de políticas de estímulo à agricultura de alimentos - que pela sua insegurança de colheita nas secas seriam uma grande fábrica de flagelados" (Agropecuária Tropical, n. 29, 1982, p. 6). Esse "conviver com as secas" seria também um argumento para superar o que seriam "mentiras redentoras que vêm desde D. Pedro II, como as obras de transposição do São Francisco" (Coelho, 1983, p. 16).

O argumento da convivência com as secas será acionado como arma de crítica política durante toda a década de 1980. O quadro abaixo apresenta trechos significativos que tratam da convivência com as secas - e do chamado à vocação pecuária das grandes fazendas - nos editoriais de edições de Agropecuária Tropical, entre 1980-1988: 


\section{Quadro 1 - Convivência com as secas nos editoriais da revista Agropecuária Tropical}

(1980-1987)

\begin{tabular}{|c|c|}
\hline $\begin{array}{l}\text { Ano / } \\
\text { edição }\end{array}$ & Resumo do editorial \\
\hline $\begin{array}{l}17^{\mathrm{a}}-\mathrm{ed} . \\
\text { jul } 1980\end{array}$ & $\begin{array}{l}\text { Eis as duas palavras-chave da solução nordestina: carne e leite, dois produtos que enfrentam } \\
\text { a seca muito mais que agricultura (...). }\end{array}$ \\
\hline $\begin{array}{l}22^{\mathrm{a}} \text { ed. } \\
\text { jan } 1981\end{array}$ & $\begin{array}{l}\text { A seca mostra o caminho contra a mistificação da água como redenção: a região pode } \\
\text { ser autossustentada retornando à sua vocação básica que é terra e gado. }\end{array}$ \\
\hline $\begin{array}{l}23^{\mathrm{a}} \text { ed. } \\
\text { out } 1981\end{array}$ & $\begin{array}{l}\text { A hora e a vez dos nordestinos: crítica aos erros nas frentes de emergência - é preciso } \\
\text { crédito para convivência com as secas: feno, silos, cacimbas, armazéns diversos. }\end{array}$ \\
\hline $\begin{array}{l}24 \stackrel{\text { a }}{e d .} \text {. } \\
\text { jan } 1982\end{array}$ & $\begin{array}{l}\text { O Nordeste, berço da civilização brasileira, que tantos homens de valor produziu, vive } \\
\text { um momento inglório (...). O solo nordestino é viável e o sertanejo sabe trilhar esse } \\
\text { caminho, os técnicos oficiais é que não o sabem (...) fracassaram, com exceção feita aos } \\
\text { projetos da Sudene (...) Implantação de um modelo de desenvolvimento fundamentado } \\
\text { na convivência com as secas (...). }\end{array}$ \\
\hline $\begin{array}{l}25^{\mathbf{a}} \text { ed. } \\
\text { mar } 1982\end{array}$ & $\begin{array}{l}\text { Chega ao quarto ano de secas (...). Um aprendizado inigualável de convivência. De um } \\
\text { lado a seca, do outro a injeção de sabedoria cultivada pelo sol (...). A consciência de que } \\
\text { o Nordeste é viável em suas atividades agropastoris, para as quais o sol é fator positivo (...). } \\
\text { Consciência de que a exploração econômica que mais consegue suportar uma grande seca } \\
\text { deveria ser oficialmente indicada, gozando de apoio creditício farto. No caso, a pecuária } \\
\text { rústica deveria ocupar o mesmo papel da Austrália, EUA e Espanha. (...). Um verdadeiro } \\
\text { caminho da redenção nordestina. }\end{array}$ \\
\hline $\begin{array}{l}27 \stackrel{\text { a }}{\text { ed. }} \text { mai } 1982 \\
\text { mai }\end{array}$ & $\begin{array}{l}\text { Assumir a seca: eis a solução (...). De D. Pedro à Sudene: todos procurando descobrir a } \\
\text { maneira de "redimir" o Nordeste de suas secas. Todos tentando transformar a terra seca } \\
\text { num oásis, tentado fazer água mesmo que viesse a salinizar, tentando fazer agricultura } \\
\text { onde se pode ter pecuária. }\end{array}$ \\
\hline $\begin{array}{l}28 \text { a ed. } \\
\text { nov } 1982\end{array}$ & $\begin{array}{l}\text { O advento do autoritarismo político (...) trouxe o vilipêndio do algodão, sisal, cana-de- } \\
\text { açúcar e couro, e trouxe êxodo rural, a drenagem de recursos do setor rural para o setor } \\
\text { urbano e manteve frentes de emergência (...). Não haveria fome com recursos para pecuária } \\
\text { e culturas resistentes à seca. }\end{array}$ \\
\hline $\begin{array}{c}34^{\mathrm{a}} \text { ed. } \\
\text { dez } 1983\end{array}$ & $\begin{array}{l}\text { Hora de ser mais nordestino: são poucos os que sabem que a caprinocultura e ovinocultura } \\
\text { de deslanados é a maior da América Latina (...). A pecuária e seus derivados sozinha poderia } \\
\text { transformar o Nordeste numa grande fonte de riqueza para todos. }\end{array}$ \\
\hline $\begin{array}{l}37^{\mathrm{a}} \text { ed. } \\
\text { jul/ago } \\
1984\end{array}$ & $\begin{array}{l}\text { A região Nordestina é habitada por heróis e semideuses (...). Conseguiram sobreviver } \\
\text { ao massacre do setor rural, às discrepâncias do modelo industrialista, à omissão oficial e } \\
\text { à permanente tentativa de desmontar a vida regional. Eles continuam de pé, porque a } \\
\text { região é viável. }\end{array}$ \\
\hline $\begin{array}{l}46^{\mathrm{a}} \mathrm{ed} . \\
\text { mar/abr } \\
1986\end{array}$ & $\begin{array}{l}\text { Depois de começar a emergir das ruínas de cinco anos consecutivos de seca - ocasião } \\
\text { em que sucumbiram } 45 \% \text { dos rebanhos e mais de } 3,5 \text { milhões de pessoas -, o Nordeste } \\
\text { poderia fornecer alimentos para o centro-sul (...). Para salvar o centro-sul e sua canícula, o } \\
\text { Nordeste é atrelado com mais rigor ao feudalismo financeiro! Dessa maneira liquidou-se a } \\
\text { chance de fornecer alimentos e solidificar convivência com o regime semiárido. }\end{array}$ \\
\hline $\begin{array}{c}54^{\mathrm{a}} \text { ed. } \\
\text { fev } 1987\end{array}$ & $\begin{array}{l}\text { A história do Brasil está repleta de realizações de homens, muito mais que governos e } \\
\text { autoridades. No Nordeste (...) engenhos são provas eloquentes dessa vontade férrea de } \\
\text { construir alguma coisa de duradouro. Também a pecuária teve suas esplêndidas fazendas } \\
\text { ao lado das culturas do sisal e algodão. Tudo isso no passado. A história registrou um lento } \\
\text { processo de marginalização nordestina (...). Os notáveis exemplos foram sepultados pela } \\
\text { bruma do tempo. Hoje, pouco se comenta sobre os majestosos engenhos do passado, } \\
\text { sobre as proezas dos homens que construíram uma civilização sobre as secas. }\end{array}$ \\
\hline
\end{tabular}

Fonte: Elaborado a partir do acervo da revista Agropecuária Tropical (1978-1989). 
Ainda na década de 1980, um outro difusor da ideia de convivência com as secas foi o jornalista pernambucano Rinaldo dos Santos, editor chefe da Agropecuária Tropical. Seu livro, A revolução nordestina: a epopeia das secas (1500-1983) (vol. I), tem proposta de ser guia de uma "verdade histórica", voltado para o meio pecuarista nordestino, marcado pela exaltação àqueles que efetivamente convivem com as secas no Nordeste, notadamente os pecuaristas, grupo que expressaria o último reduto da autêntica brasilidade, e que também remete à exaltação do período da "civilização do couro" do Brasil colonial (Santos, 1984, p. 64). A evocação dessa ordem social passada estaria viva mesmo nas ruínas das antigas casas dos "coronéis", "ruínas essas que remetem a um passado de plena convivência com as secas" (Santos, 1984, p. 66).

Contrariando as expectativas de Santos (1984), essa riqueza não seria recuperada ${ }^{14}$. Seu declínio seria aprofundado numa crise, não só econômica, mas de legitimidade de um poder nas últimas décadas do século XX. Esse momento da redemocratização brasileira foi um "gargalo" para os pecuaristas, anunciado com o desmonte fiscal da Sudene, acompanhando cenário orçamentário e de crises inflacionárias no país. A crise aprofundou-se pelo avanço da concorrência de fibras sintéticas e a proliferação de pragas no algodão, que consorciava produção com a pecuária.

Finalizando esse tópico, é possível, a partir da análise das edições da Agropecuária Tropical e da obra de Santos (1984), afirmar que foi produzida uma bandeira da convivência com as secas em defesa da grande propriedade rural. Essa ideia está sintonizada à visão de mundo de uma elite pecuarista que se diz representante de uma brasilidade sertaneja, de um "autêntico" sertão do Nordeste. Firmado esse entendimento, passo agora à análise e exercício comparativo com outra visão de convivência com as secas, construída a partir da década de 1980 entre setores da igreja católica, movimentos sociais e ONGs.

${ }^{14} \mathrm{Na}$ crise que ameaçava seu status e distinção enquanto grupo social dominante, a própria Agropecuária Tropical encerrara a década de 1980 "alugando" suas páginas para outros setores pecuaristas do país. Isso fez com que fossem retiradas as pautas da revista sobre a região Nordeste. 


\section{Semiárido como terra prometida: fé, política e resistência em convivência com as secas}

Uma forte contraposição ao paradigma de combate às secas vai ser construída em setores que eram acusados pelos editoriais de Agropecuária Tropical de serem "clérigos comunistas que cultuam a pequena propriedade" (Agropecuária Tropical 24a ed., 1981, p. 8). Como aponta Moreira Neto (2013), além da influência de trabalhos de Guimarães Duque, José Américo e Josué de Castro, esse conceito político de convivência com o semiárido tem uma raiz política nas Comunidades Eclesiais de Base (CEB). Foi essa bandeira que agregou pastorais, ONGs e movimentos sociais de luta por reforma agrária ao final do século XX. Com visibilidade desde o final da ditadura militar, esses grupos produziram redes políticas que firmaram um eficiente consenso na esfera pública de que conviver com as secas passa não apenas pela reinterpretação do fenômeno da estiagem, mas também pelo empoderamento de grupos sociais que foram marginalizados em razão da concentração fundiária e dos projetos de açudagem usados para combater as secas durante quase todo o século XX. No antes, o sertão, região dos saques, onde circulavam corpos de retirantes famintos, no máximo aproveitados em frentes de trabalho desastrosas; no agora, o semiárido, local de experiências de manejo na caatinga, plantio em sistemas racionais e melhoria das condições alimentares e do padrão de renda das famílias de agricultores familiares (Moreira Neto, 2013, p. 9).

Nesse sentido, a relação com o passado da grande propriedade da terra é de crítica, superação e ruptura: tão valorizada pela elite pecuarista, a centenária ordem social da "civilização do couro" é duramente criticada nessa convivência com o semiárido de raiz pastoral popular. Um argumento central é de viés ecológico e político: a grande propriedade do semiárido e sua pecuária bovina extensiva, praticada há séculos, é responsável por agravar a desertificação, privatizando e deixando vulneráveis os recursos naturais do semiárido. O latifúndio é acusado de marginalizar a agricultura familiar e de abraçar o modelo tecnicista e usuário de agrotóxicos da 
"revolução verde" (Duque, 2008, p. 133). Nesse viés, a elite pecuarista do Nordeste é protagonista desse "sertão arcaico" - da grande propriedade, do familismo, das lutas de "coronéis", do voto de cabresto e dos recursos das obras contra as secas.

A convivência com o semiárido enquanto superação política de uma dívida socialmente excludente leva a um novo conceito civilizatório não apenas de um fenômeno natural e cíclico, mas de toda uma região. $\mathrm{O}$ livro de Roberto Malvezzi (2007), Semiárido: uma visão holística, na linha da Pastoral da Terra, dedica seus capítulos a explicar esse novo conceito de semiárido que supera a história de concentração fundiária e hídrica. $\mathrm{O}$ autor, membro da CPT, alerta que o combate às secas ainda é o modelo vigente: a obra da transposição do rio "símbolo" da região, o São Francisco, à época da publicação do livro, estava sendo iniciada e sendo alvo da crítica de organizações sociais e pastorais, inclusive com uma greve de fome de religiosos em protesto na região de Cabrobó/PE ${ }^{15}$. Diante dessa insistência em obras redentoras de combate às secas, seria preciso retomar a resistência enraizada por "um catolicismo sertanejo". Daí, Malvezzi (2007) revisita movimentos messiânicos liderados por personagens populares, como Antônio Conselheiro e Pe. Cícero, além de apresentar propostas para formação em organização comunitária, educação contextualizada à realidade local.

Esses fundamentos descritos por Malvezzi (2007) são os pilares de redes como a Articulação Semiárido Brasileiro (ASA). Criada em 1999, e tendo como documento fundador uma série de compromissos na "Declaração para o Semiárido", a ASA tem origem na efetivação de reivindicações e lutas por uma política de intervenção constante e não apenas emergencial diante das secas. Essa luta teve um marco inicial em 1993, com a ocupação do prédio da Sudene (em Recife) por 300 entidades que direcionavam ações

15Ver: https://atarde.uol.com.br/bahia/noticias/1248440-bispo-de-barra-retoma-greve-defome-contra-transposicao-do-sao-francisco. Outro momento interessante dos embates que envolveram a obra da Transposição foi um debate no programa televisivo Roda Viva (em 15 de julho de 2005), com o então ministro da Integração Ciro Ferreira Gomes. A entrevista está disponível na íntegra em: https://www.youtube.com/watch?v=IYVfkLkKzBU\&t=624s. 
e debates para o Seminário, dentro do chamado Fórum Nordeste (Duque, 2008, p. 135). A ASA também se insere no que Diniz e Piraux (2011) chamam de "experimentalismo institucional": uma construção processual de diálogos entre governo e sociedade civil, particularmente nos mandatos presidenciais de Lula, a partir de 2003. Daí a efetivação de quadros dentro de ministérios e de políticas públicas - programas de cisternas (P1MC e P1+2), o Programa Nacional de Agricultura Familiar (Pronaf), o Projeto Dom Helder Câmara, dentre outros (Diniz; Piraux, 2011, p. 235), todos com linhas de ação dentro do paradigma da convivência com o semiárido.

A vertente "pastoral" da convivência com as secas defende não só a viabilidade econômica, mas a valorização de grupos e práticas sociais enquadradas como uma lógica - as vezes chamada de sertaneja ou camponesa - que indica uma agricultura e pecuária adaptadas à pequena propriedade, suas formas de organização comunitária e saberes locais sobre as secas. Em um acervo de 30 edições (entre 2009 e 2013) do boletim informativo O Candeeiro do Programa Uma Terra e Duas Águas $(\mathrm{P} 1+2)^{\mathbf{1 6}}$, é possível acessar certos esquemas de percepção. Um deles é a experiência de coletivos para construção de cisternas e aprendizados na agroecologia e de como essas tecnologias sociais marcam transformações em histórias de vida de pequenos agricultores. A narrativa segue um roteiro similar: agricultores que antes trabalhavam e eram explorados nas grandes fazendas ganham autonomia e "despertam" saberes ao entrar nas associações e projetos junto à ASA: a experimentação agroecológica, bancos de sementes crioulas e sistemas de mandalas com água das cisternas se enredam nos chamados quintais produtivos: "um pleno aproveitamento da pequena propriedade, segundo conhecimento local de uma família de pequenos agricultores para convivência com as secas" (Asa, 2014, p. 2).

O paradigma de combate às secas, além de prejudicial, no sentido econômico e ambiental, também é criticado em razão de seu alto grau de

${ }^{16}$ Disponível no site da ASA, O Candeeiro é um jornal informativo das ações, cursos, capacitações e experimentações junto às políticas de agroecologia, cisternas e outras mobilizações sociais. Ver: https://asabrasil.org.br/acervo/o-candeeiro?artigo_id=8034. 
machismo: as propostas de grandes obras e projetos redentores, sejam de açudagem ou de perímetros irrigados, jamais reconheceram a potência criativa das mulheres agricultoras experimentadoras do semiárido. Essas são apresentadas como mulheres sertanejas que têm a legítima autoridade e vivência com as secas:

Dona Lenita: história e testemunho das mulheres no Semiárido brasileiro

No alto da comunidade Evangelista, no município de Buíque, em Pernambuco, moram Dona Otacília Brasileira Avelino de Sampaio e três de seus cinco filhos. A história de Dona Lenita (...) se confunde com a história de muitas mulheres guerreiras que moram no semiárido brasileiro. Foi por meio de sua garra e disposição para o trabalho que conta como ajeitou a vida dos 5 filhos que Deus lhe deu (...). Do inverno de 2010 pra cá, a família vem administrando a água para a produção de alimentos para a casa e para a venda. Também aprenderam a economizar a água da cisterna fazendo canteiros econômicos. (...) É junto da cisterna calçadão que Dona Lenita mantém também suas plantas de remédio: hortelã da folha grossa, hortelã miúda, capim santo, mostarda, girassol e recentemente plantou colônia que trouxe de sua última visita de intercâmbio (...) Dona Lenita ensina que um agricultor não pode viver sem os animais. Eles são como uma poupança para a família, além de aproveitar as sobras dos roçados e das hortaliças (Dona Lenita...., 2011, p. 1-4).

Este tópico tratou de como foi construída uma convivência com o semiárido que orienta uma frente de mobilizações coletivas de crítica à concentração fundiária no Nordeste e, logo, entra em atrito com representações políticas e visões de mundo alinhadas com valores da elite proprietária rural. Contudo, mesmo antagonistas e inconciliáveis, há algumas convergências no horizonte das diferentes convivências com o semiárido que foram apresentadas e analisadas. É disso que trata a seção seguinte deste artigo. 


\section{Mapeando o campo da convivência com o semiárido}

Desde o tópico inicial, ao enfatizar como grandes pecuaristas nordestinos são agentes ativos de criação de uma bandeira de convivência com as secas, tento mostrar a convivência com o semiárido como um campo de lutas e não como um conceito fechado, harmônico e linear, como pretendem seus diversos defensores. Como em todo campo, há disputas de recursos materiais e simbólicos entre setores conservadores e os defensores de "heresias" sobre o tema da superação do modelo de combate às secas. De um lado, é fato que há não há possibilidade de conciliação entre versões de convivências com a seca por parte dos pecuaristas e por parte dos movimentos sociais. O "recorte", nos projetos da Sudene, visando a evocação da grande propriedade de terra dos pecuaristas vem junto à desqualificação de toda e qualquer política voltada à pequena propriedade familiar - seja por reforma agrária, crédito rural ou políticas de cisterna. Por sua vez, pautas de defesa das organizações sociais e movimentos que orbitam a ASA lançam artilharia política contra aqueles que se consideram "herdeiros" do Nordeste rural latifundiário. Esses grupos são vistos como beneficiários históricos das injustiças e desigualdades reproduzidas pelos modelos de combate à seca. Outro ponto importante de divergência trata dos protagonistas da convivência com o semiárido: os pecuaristas valorizam as biografias dos "patriarcas", que seriam guardiães de autênticos conhecimentos e tradições da convivência com as secas, da "sociedade do couro". Já nas cartilhas e produções acadêmicas, alinhadas à ASA, são exaltadas as mulheres camponesas, as "agricultoras experimentadoras", como portadoras legítimas dos saberes agroecológicos, dos quintais e fundos de pasto, em suma, de estratégias locais e comunitárias para conviver com as secas.

Contudo, as sociedades de representação pecuarista e organizações sociais de luta por reforma agrária são unificadoras e geradoras de discursos e posicionamentos políticos no campo da convivência com o semiárido. Ambas, por diferentes linguagens, defendem uma classificação econômica, 
identitária e política do semiárido enquanto espaço vocacionado para o rural. As divergências e "convergências" podem ser ilustradas em como diferentes agentes sociais se distribuem numa representação de campo das convivências com semiárido demonstrada no diagrama abaixo:

Figura 1 - Campo da convivência com o semiárido

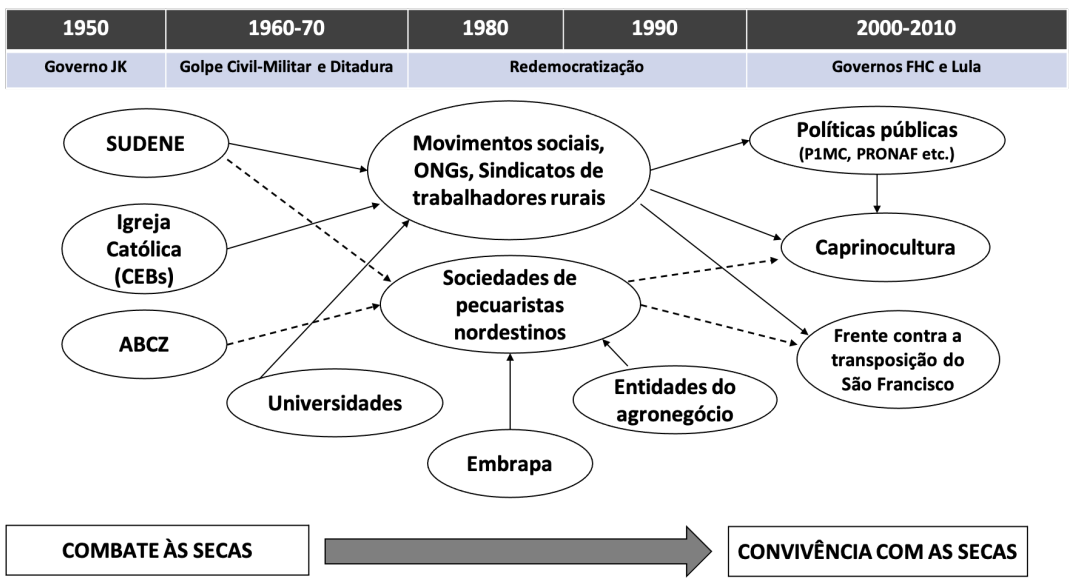

Fonte: Meneses, 2018.

É atravessando grupos antagônicos e de visões políticas inconciliáveis que se legitima uma força motriz do campo da convivência com as secas: imposição de classificação do semiárido nordestino como região de vocação rural. Essas são visões de mundo indispensáveis para a própria existência e continuidade do campo de lutas: não participa do "jogo" quem não incorporar a ideia de que o semiárido sempre foi e sempre será destinado naturalmente a uma vocação rural. Essa ideia é premissa que consegue abarcar tanto a agenda política das demandas de agroecologia, cisternas de placa, fundos de pasto e quintais produtivos quanto o projeto das grandes fazendas modelo de raças de bovinos e caprinos com rusticidade e alto 
valor de mercado. Isso explica em parte por que todos nesse campo da convivência com as secas têm posições similares contra a Transposição do São Francisco e também partem em defesa de uma vocação que seria "natural" do semiárido para a caprinocultura (Meneses, 2020). Dentro da configuração de um campo (Bourdieu, 2004a; 2004b), o termo convivência com o semiárido é crivado de disputas em um microcosmo de agentes e relações sociais, suas forças internas e externas. Mas o conflito não significa rupturas e desordens: a partir da Figura 1 também é possível reconstruir diversos caminhos pelos quais vem sendo produzido e legitimado um sistema de percepções sociais comuns - a do semiárido como região destinada a uma vocação rural agropecuária - mesmo entre adversários políticos.

Essa illusio é condição prévia para estar no jogo e assim disputar e acessar recursos materiais e simbólicos de ações econômicas, de políticas públicas a trajetórias de poder distintas nos quadros do Estado. Uma das mais eficazes crenças produzidas nesse campo da convivência com o semiárido é negar a seca como um fenômeno que também afeta o eixo urbano do Nordeste. Os problemas de abastecimento onde atualmente vive a maioria da população do semiárido brasileiro não é pensado, nem sequer colocado, como politicamente relevante entre diversos atores políticos e até acadêmicos que produzem e legitimam diversas convivências com o semiárido.

\section{Considerações finais}

Ao analisar e mapear diferentes versões da convivência com o semiárido, é preciso ir além do que já colocaram clássicos do tema sobre elite, poder e secas no Nordeste. A reconstrução feita através de revistas, como a Agropecuária Tropical, mostra como elites pecuaristas nordestinas retomam uma visão legitimadora de Nordeste, usando de uma bandeira da convivência com o semiárido gestada em um aparente paradoxo entre "a saudade e rusticidade". Trata-se de como uma elite ergue seus recursos sociais de distinção sobre valores que evocam tradição e saudosismo, mas que são 
produtos estritamente modernos: conviver com as secas passa pela fazenda pecuarista e sua ordem social passada da "civilização do couro". Conviver com as secas implica também que esse espaço da grande propriedade seja alvo de empreendimentos modernizantes via pecuária adaptada às secas. Nesse movimento, visões de propriedade, seca e Nordeste "vão e voltam" na realidade da prática, ou seja, são incorporadas e operadas por agentes na construção de uma realidade, visão de mundo e ordem social. É esse lugar da prática e da agência que tende a ficar obscuro nas teses centrais, tanto de autores mais próximos a visões marxistas, quanto na visão de viés foucaultiano sobre o Nordeste e o semiárido. Respeitadas as suas grandes contribuições ao debate, todas essas análises seguem o caminho de autonomizar um imaginário regionalista e, no fim, ficam como se fossem nuvens "reificadas" - seja por discursos de saber e poder, ou por fenômenos ideológicos nas relações de produção - que desabam não chuvas, mas imagens de secas e regionalismos. Tudo se move como se as ideias e valores regionalistas fossem um espectro que ronda acima das cabeças de agentes sociais vistos sem capacidade de agência.

No plano político, o debate que propõe este artigo se contrapõe a toda e qualquer visão que coloca a bandeira de convivência com o semiárido como se fosse uma descoberta espontânea, harmônica, de vocações rurais e também "naturais" de toda uma região. Para tentar fugir dessas imposições, é importante uma análise distanciada de argumentos que quase soam como propaganda, com pouco grau de crítica sobre ideias e experiências classificadas como exemplo de convivência com o semiárido. Importante demarcar que, ao criticar sociologicamente a posição dos grupos a favor da bandeira da convivência com as secas e enfatizar como foi produzida uma versão dessas ideias do "lado" de grandes pecuaristas, não busco neutralidade nem faço nenhum engajamento político favorável às elites. Proponho aqui uma tentativa de sair de um lugar comum, devolvendo um pouco de maleabilidade e energia política à ideia de convivência com o semiárido, expondo seus conflitos e contradições inerentes, não para destruir seu potencial, mas para compreender como elites condicionam o 
poder criativo dessa ideia a uma lógica de dominação. Um alerta para como estão sendo atualizados projetos políticos que restringem capacidades para combater as desigualdades sociais, agora sob nova aparência "convivida" e, portanto, naturalizada da relação entre elites, poder e secas no semiárido Nordestino.

Valdênio Freitas Meneses Doutor em Ciências Sociais pelo CPDA/UFRRJ. Bolsista Capes/ Brasil e Pos-doutorando vinculado ao Laboratório de Estudos de Poder e Política (LEPP/ PPGS/UFS). Atualmente professor do departamento de Direito da Uninassau, Campina Grande, PB, Brasil.

$\bowtie$ valdeniofmeneses@gmail.com

\section{Referências}

1. ALMEIDA, Jalcione. A sociologia e as mudanças climáticas. Editorial. Sociologias, Porto Alegre, v. 21, n. 51, p. 9-17, 2019. https://doi.org/10.1590/151745220215100

2. ALBUQUERQUE JR. Durval M. A invenção do Nordeste e outras artes. São Paulo: Cortez, 2011.

3. ALBUQUERQUE JR., Durval M. Nordestino de saia rodada e calcinha preta ou as novas faces do regionalismo e do machismo no Nordeste. In: QUEIROZ, André (org.) A reinvenção do Nordeste, v. 1. Fortaleza: SESC-Ceará, 2010. p. 61-86.

4. ARTICULAÇÃO SEMIÁRIDO BRASILEIRO. História de quintais: a importância do arredor de casa na transformação do semiárido. Recife: ASA, 2014.

5. BACELAR, Tânia A. Economia do semiárido: a crise como oportunidade. Revista Coletiva, n.15, p. 5-19, 2010.

6. BOURDIEU, Pierre. Os usos sociais da ciência: por uma sociologia clínica do campo científico. São Paulo: UNESP, 2004a.

7. BOURDIEU, Pierre. A produção da crença: contribuição para uma economia dos bens simbólicos. São Paulo: Zouk, 2004 b.

8. BRUNO, Regina. Agronegócio, ruralismo e relações de poder. Rio de Janeiro: Mauad X, 2009. 
9. CAMPOS, José. Secas e políticas públicas no semiárido: ideias, pensadores e períodos. Estudos Avançados, v. 28, n. 82, p. 65-88, 2014.

10. CHAMPAGNE, Patrick. Séminaires sur le concept de champ - 1972-1975. Actes de La Recherche en Sciences Sociales, n. 200, p. 4-37, 2013.

11. COELHO, Jorge. Nordeste: sempre uma história mal contada. Agropecuária Tropical, n. 35, p. 14-18, 1983.

12. CUNHA, Luís H.; PAULINO, Jonatta S. Convivência com o semiárido: um novo paradigma para políticas públicas no Nordeste? In: NEVES, Delma; GOMES, Ramonildes; LEAL, Pedro (orgs.). Quadros institucionais em políticas públicas. Campina Grande: Eduepb, 2014. p. 27-59.

13. DINIZ, Paulo C.; PIRAUX, Marc. Das intervenções de combate à seca às ações de convivência com o semiárido: trajetória de experimentalismo institucional do semiárido brasileiro. Caderno de Estudos Sociais, v. 26, n. 2, p. 227-238, 2011.

14. DONA LENITA: história e testemunha das mulheres do semiárido brasileiro. O Candeeiro, v. 5, n. 69, p. 1-4, 2011.

15. DUQUE, Ghislaine. Convivência com a seca: contribuição da articulação do semiárido (ASA). Desenvolvimento e Meio Ambiente, n.17, p.133-140, 2008.

16. FERREIRA, Angela L.; DANTAS, George A.F.; FARIAS, Helio T. Por uma história técnica das secas. Revista ConViver (Fortaleza), v. 6, p. 249-27, 2009.

17. FURTADO, Celso. Uma política de desenvolvimento econômico para o Nordeste (GTDN). In: FURTADO, Rosa F. de A. (org.). O Nordeste e a saga da Sudene (1958-1964), v. 3. Arquivos Celso Furtado. Rio de Janeiro: Contraponto, 2009. p. 83-164.

18. LEAL, Natacha S. Nome aos bois: zebus e zebuzeiros em uma pecuária brasileira de elite. São Paulo: Hucitec, 2016.

19. LEWIN, Linda. Política e parentela na Paraíba. Um estudo de caso da oligarquia de base familiar. Rio de Janeiro: Record, 1993

20. MALVEZZI, Roberto. Semi-árido: uma visão holística. Brasília: Confea, 2007.

21. MARCONDES, Renato; DANDARO, Fernanda. Obras públicas no contexto regional: secas e gastos no Nordeste brasileiro (1860-1940). Revista Economia do Nordeste, v. 49, p. 113-127, 2018.

22. MEDRADO, Joana. "A Guerra contra o Zebu": notas sobre o animal que dividiu as elites pecuaristas brasileiras. Ruris, v. 9, n. 2, p. 270-302, 2015.

23. MENDONÇA, Sônia. Ruralismo. In: MOTTA, Márcia M. Dicionário da terra. Rio de Janeiro: Civilização Brasileira, 2005. p. 410-414.

24. MENESES, Valdênio. Um macarthismo hidráulico contra a Sudene: notas sobre a disputa entre o Senador Argemiro de Figueiredo e Celso Furtado (19591963). Cadernos do Desenvolvimento, v. 11, p. 83-102, 2017. 
25. MENESES, Valdênio. Saudade e rusticidade: reconversões sociais e convivência com as secas entre elites pecuaristas do Cariri Paraibano. Tese (Doutorado em Desenvolvimento Agricultura e Sociedade), Universidade Federal Rural do Rio de Janeiro, 2018.

26. MENESES, Valdênio. O semiárido do patriarca: narrativas biográficas na elite pecuarista do Cariri Paraibano. Revista Raízes: Ciências Sociais e Econômicas, v. 38, p. 7-22, 2019.

27. MENESES, Valdênio. "Admirável Bode Novo": regionalismo e ruralismo em defesa da caprinocultura no semiárido nordestino. Estudos Sociedade e Agricultura, v. 28, n. 1, p. 109-135, 2020.

28. MOREIRA NETO, Mariana. Outro sertão: fronteiras da convivência com o semiárido. Recife: Massangana, 2013.

29. NUNES, Aldo Branquinho. Currais, cangalhas e vapores: dinâmicas de fronteira e conformação das estruturas social e fundiária nos "Sertões da Borborema" (1780-1920). Tese apresentada no Programa de Pós Graduação em Ciências Sociais (PPGCS/UFCG), 2016

30. OLIVEIRA, Francisco de. Elegia para uma re(li)gião: Sudene, Nordeste, planejamentos e conflito de classes. Rio de Janeiro: Paz e Terra, 1981.

31. OlIVEIRA, Pedro. Illusio: aquém e além de Bourdieu. Mana, v. 11, n. 2, p. 529- 543, 2005.

32. LEÃO REGO, Walquíria L.; PINZANI, Alessandro. Vozes do Bolsa Família: autonomia, dinheiro e cidadania. São Paulo: Editora UNESP, 2014.

33. RIBEIRO, Eduardo. Agregados e fazendas no nordeste de Minas Gerais. Estudos, Sociedade e Agricultura, v. 18, n. 2, p. 393-433, 2010.

34. SANTOS, Rinaldo. A revolução nordestina: a epopeia das secas (1500-1983). Recife: Editora Tropical, 1984.

35. TADDEI, Renzo; HAINES, Sophie. Quando climatologistas encontram cientistas sociais: especulações etnográficas sobre equívocos interdisciplinares. Sociologias, v. 21, n. 51, p. 186-209, 2019. https://doi.org/10.1590/151745220215107

36. TEIXEIRA DA SILVA, Francisco C. Pecuária e formação do mercado interno no Brasil Colônia. Revista Estudos Sociedade e Agricultura, v. 5, n.1, p. 119-156, 1997.

37. VESENTINI, José. O conceito de região em três registros. Exemplificando o Nordeste brasileiro. Confins Revue Franco-brésilienne de Géographie, v. 34, p. 1-13, 2012.

Recebido em: 27 nov. 2019.

Aceito em: 9 abr. 2020. 
